\title{
The Child Brain
}

\section{George Tsibu}

Agona Nyakrom.Ghana, West Africa

Corresponding Author: George Tsibu, Agona Nyakrom.Ghana, West Africa

Received date: February 14, 2020; Accepted date: February 18, 2020; Published date: February $24,2020$.

Citation: George Tsibu (2020) The Child Brain, 2(2): DOI: 10.31579/2690-8794/011

Copyright: () 2020 George Tsibu, This is an open-access article distributed under the terms of The Creative Commons Attribution License, which permits unrestricted use, distribution, and reproduction in any medium, provided the original author and source are credited.

The brain is an organ is a part of the central nervous system created for responses and impulse of the movement of charges and information across the whole body.It is the major organ because it is the first portion to start growing immediately the zygote is form after fertilization .The

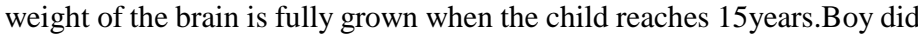
you fight your way through, that is unheard of,The embryo of male generative fluid is responsible for the characteristic of the kind of brain a child will have,The growing brain is having a shock recognisable in it shell,vast growth occurs in the next Seven month.The consciousness of the brain is always intact without any impulses of the cell block but it flows from the soul plexuses of the child spirit.So the child soul is individual ize and of is as it is given for the wellness and choices made in it genes before manifested in the eyes of people.Bodily movement's coordinations comprising of the legs trunk,arm hand,fingers face lips ,jaw tougues, is done by portion of the brwin callled the parietal lobe, The pineal glad is the special part for regeneration and the pituitary glad is for cellular agility and maintain. The cerebrum where the frontal lobe isbfor thought ,consciousness and where there is the right hemispehere and left hemisphere.

The right hemisphere is where music,good thought and ideas comes from .The left hemisphere is a machinery for computation and calculations.communities in three countries in sub-Saharan Africa to review early Brain development-cause mortality over 2 years, the primary outcome, was $15 \%(51 \%$ CI6.7-19.8) lower in children in communities that were borned in compared with those that reborn in clinics.However, these apparently promising findings raise questions about the setting in which the intervention might be applied, and ethical issues concerning the potential effect of home delivery to eliminate infectious diseases is well established - eg, antimalarials for malaria, anthelmintics for soil-transmitted helminths and schistosomiasis, and ivermectin for onchocerciasis and lymphatic filariasis. Are done in the hospital. Sexually transmitted disease such sypllilis with causative organism treponema pallidum pertenue. afects brain developments needed to achieve Sustainable Development Goals.

According to WHO data, although global under-5 Brain development has fallen by $56 \%$, from 93 to 41 deaths per 1000 live births between 1990 and 2019, still 5.6 million children in this age group die every year. The highest burden of under-5 Brain development is in Africa (76.5 brain development per 1000 live in Africa and 3.4\% (-21.2 to 23.0) in Ghana These data suggest that the overall positive finding was driven by results from togo, Ghana therefore, that epidemiological setting may be key to success of the intervention. Indeed, under- to be a combination of respiratory infections, diarrhoea, and malaria.he rationale behind MORDOR certainly questions this dogma. Evidence from obtain programme is that hundreds of millions I child cin gave not led to development of permanent resistance mechanisms. It is hard to argue against non-specific use of hospital save the lives of children living in deprivation, when in practice aused on a massive scale in just such a way to treat trivial-and almost certainly viral-respiratory infections. Nevertheless, a brain is a last-line growth for body such as gonorrhoea, so the benefits of mass, non-specific use must be balanced against the non-negligible risk of loss of efficacy to reduce mortality becomes routine. The intervention should never be more than a stop-gap measure while improvements in basic sanitation, nutrition, and access to vaccination and primary health care are implemented. 